\title{
Governança de Turismo de Base Comunitária e estudo dos entraves para a consolidação de duas comunidades em Recife (Pernambuco, Brasil) sob a luz do Modelo de Análise da Governança
}

\section{Resumo}

Pollyanna Fraga Gracianoa Luciana Araújo de Holandab

A partir da proposta de uma nova visão paradigmática do fenômeno turístico, o turismo de base comunitária (TBC) incrementa a atividade turística inspirada no desenvolvimento sustentável e no protagonismo dos atores locais, contribuindo para a geração alternativa de renda e melhoria da qualidade de vida das comunidades. Embora sejam constantemente estudadas e debatidas pela academia, as iniciativas de TBC enfrentam dificuldades para consolidar-se no mercado turístico e tendem a fenecer. Pesquisas realizadas na área apontam que a governança é um dos obstáculos para esta consolidação. No Recife, duas comunidades, a Bomba do Hemetério e a Ilha de Deus, desenvolvem iniciativas de TBC, porém ambas não se firmaram como destino turístico regular. Logo, este estudo analisa a governança dessas iniciativas recifenses por meio da aplicação do Modelo de Análise da Governança (MAG) do TBC, adotando como construtos a participação, a transparência e a eficácia. A pesquisa caracteriza-se como qualitativa, descritiva e explicativa. A coleta de dados ocorreu por meio de observação, pesquisa documental e entrevistas semiestruturadas. Para o tratamento dos dados coletados, empregou-se a análise de conteúdo do tipo categorial, obedecendo ao critério lexical. Entre os entraves para a consolidação das iniciativas recifenses destacam-se os conflitos internos, baixo relacionamento com o poder público e a alta dependência externa, inclusive de redes.

Palavras-chave: Turismo de Base Comunitária; Governança de Turismo; Destino turístico; Comunidade local; Desenvolvimento local.

\section{Abstract \\ Community-based tourism governance and study of the barriers to the consolidation of two communities in Recife (Pernambuco, Brazil) in light of the Governance Analysis Model}

Based on a new paradigmatic vision of tourist phenomenon, the Community-Based Tourism (CBT) increases the tourist activity inspired by sustainable development and by the protagonism of local actors, contributing to alternative income generation and improving the quality of life of communities. Despite being constantly studied and debated by the academy, such CBT initiatives face difficulties to consolidate themselves in the tourist market and tend to decline. Research carried out in the field indicates that governance is one of obstacles to consolidation. In the municipality of Recife, two communities, Bomba do Hemetério and Ilha de Deus, develop CBT initiatives but

a. Mestre em Hotelaria e Turismo pela Universidade Federal de Pernambuco (UFPE). Recife, Pernambuco, Brasil. E-mail: lyafraga@gmail.com

b. Doutora em Administração pela Universidade Federal de Pernambuco (UFPE). Docente dos cursos de Turismo e Hotelaria na Universidade Federal de Pernambuco (UFPE). Recife, Pernambuco, Brasil. E-mail: luciana.holanda@ufpe.br 
neither was established as a regular tourist destination. Therefore, this study analyzes the governance of Recife CBT initiatives by applying the CBT governance analysis model (GAM), adopting participation, transparency, and effectiveness as constructs. The research is characterized as qualitative, descriptive, and explanatory. The data collection techniques used were observation, document research, and semi-structured interviews. For data analysis, a content analysis by categorization, following lexical criterion was conducted. Among the obstacles to the consolidation of Recife initiatives we highlight the internal conflicts, low relations with public authorities, and high external dependence, including networks.

Keywords: Community-Based Tourism (CBT); Tourism Governance; Tourist destination; Local community; Local development.

\section{Resumen}

Gobernanza del turismo comunitario y el estudio sobre los obstáculos para la consolidación de dos comunidades en Recife (Pernambuco, Brasil) a la luz del Modelo de Análisis de Gobernanza

A partir de la propuesta de una nueva visión paradigmática del fenómeno turístico, el Turismo Comunitario (TC) fortalece la actividad turística inspirada en el desarrollo sostenible y en el protagonismo de los actores locales, contribuyendo a la generación alternativa de ingresos y mejora de la calidad de vida de las comunidades. Sin embargo, aunque son constantemente estudiadas y debatidas por la academia, las iniciativas de TC enfrentan dificultades para consolidarse en el mercado turístico y tienden a desvanecerse. Las investigaciones realizadas en el área indican que la gobernanza es uno de los obstáculos para esta consolidación. En Recife, las comunidades de Bomba do Hemetério e Ilha de Deus desarrollan iniciativas de TC, pero ambas no se han consolidado como un destino turístico habitual. Por lo tanto, esta investigación busca analizar la gobernanza de estas dos iniciativas en Recife aplicando el modelo de análisis de gobernanza de turismo comunitario (MAG do TBC) con base en los constructos de participación, transparencia y eficacia. Esta investigación es cualitativa, descriptiva y explicativa. La recolección de datos se realizó por investigación documental, observación y entrevistas semiestructuradas. Para el tratamiento de los datos recolectados se utilizó el análisis de contenido de tipo categórico, obedeciendo al criterio léxico. Entre los obstáculos para la consolidación de las iniciativas de Recife, destacan los conflictos internos, las bajas relaciones con las autoridades públicas y la alta dependencia externa, incluso de redes.

Palabras clave: Turismo Comunitario; Gobernanza del Turismo; Destino turístico; Comunidad local; Desarrollo local.

\section{INTRODUÇÃo}

O Turismo de Base Comunitária (TBC) caracteriza-se como um modelo de desenvolvimento turístico focado nos recursos humanos, naturais e de infraestrutura endógenos à localidade, em que a população local tem o protagonismo na gestão de bens e serviços turísticos (Fabrino, Nascimento, \& Costa, 2016). 0 TBC evidencia-se como uma alternativa para as localidades conciliarem a oferta de serviços turísticos com a melhoria da qualidade de vida das comunidades (Zielinski, Kim, Botero, \& Yanes, 2020).

Muitos desafios à consolidação das iniciativas de TBC são descritos na literatura: despreparo das comunidades; improviso e ausência de profissionalismo; desconhecimento do mercado, de instrumentos de gestão e dos 
processos; dificuldades de comunicação; falta de informação; falta de estratégias de formatação e comercialização do produto; e falta de compreensão das relações com ambiente exógeno; todos são fatores que levam ao enfraquecimento e desconhecimento destas iniciativas (Albuquerque, 2016; Bursztyn \& Bartholo, 2012; Mielke \& Pegas, 2013) que somente obterão êxito ao gerar receitas para as comunidades (Mayaka, Croy, \& Cox, 2018). Portanto, necessita-se compreender a consolidação das iniciativas de TBC como a capacidade de ser autossuficiente financeiramente, contribuindo para a diminuição da pobreza e emancipação social.

De acordo com o Ministério do Turismo (MTUR, 2010), os destinos turísticos de TBC possuem um ciclo de vida que inclui: investimento, desenvolvimento, consolidação e declínio, que ocorre pela massificação local. Bursztyn e Bartholo (2012) explicam que o envolvimento da gestão pública permite acesso às linhas de crédito, à assistência técnica e à capacitação profissional, facilitando a comercialização destes produtos. Ademais, este desafio não se restringe às comunidades, dada a necessidade da participação de outros atores para gerar os benefícios esperados. Assim, a formação de redes dos atores desembaraça a aproximação do poder público, favorecendo o planejamento estratégico (Bursztyn \& Bartholo, 2012).

Gómez, Falcão, Castillo, Correia \& Oliveira (2015) apontam que a organização dos atores contribui para uma boa governança. Okazaki (2008) aborda a relevância da participação, do poder, da colaboração e do capital social como elementos essenciais à consolidação. Em 2011, um relatório de monitoramento do TBC da Universidade Estadual do Rio de Janeiro (UERJ) avaliou os projetos selecionados pelo Edital no 01/2008 do MTUR, identificando o acesso ao mercado, a governança e o monitoramento como os principais entraves à consolidação do TBC (Mielke \& Pegas, 2013).

Albuquerque (2016) afirma que as iniciativas consolidadas apresentam diversidade na oferta de serviços turísticos; maturidade entre os atores; autogestão comunitária da atividade e número de visitantes adequado ao contexto. Entretanto, o TBC não almeja somente a consolidação pela lucratividade, mas o desenvolvimento social. Diante do exposto, o artigo objetiva analisar a governança das iniciativas recifenses de TBC pela aplicação do modelo de análise da governança (MAG) do TBC proposto por Albuquerque (2016). Logo, identificaram-se duas comunidades em diferentes fases de implantação do TBC no Recife-PE, sendo uma desenvolvida por agentes endógenos - a Ilha de Deus - e outra por agentes exógenos - a Bomba do Hemetério, porém, ambas com dificuldades em consolidar-se no mercado.

A investigação utilizou-se da pesquisa qualitativa, descritiva e explicativa, coletando dados através da observação, pesquisa documental e entrevistas semiestruturadas numa proposta de triangulação dos dados (Creswell, 2016), por meio de um corpus composto por materiais orais e audiovisuais. A interpretação dos dados seguiu a Análise de Conteúdo de Bardin, (2016), aplicando a técnica de categorização em seu critério lexical. 0 presente artigo possui relevância teórica, pois aborda uma lacuna da produção científica ao estudar a governança no processo de consolidação das iniciativas de TBC no mercado turístico, bem como, a importância prática para efetiva atuação das comunidades neste processo, contribuindo para redução do declínio destas iniciativas. 


\section{REFERENCIAL TEÓRICO}

\section{Governança e suas relações com o TBC}

A governança é um conceito polissêmico que, apesar de abranger instituições governamentais, possibilita a interação de outros atores com objetivos em comum (Anjos \& Kennell, 2019). Cozzolino, Irving e Soares (2015) concebem governança como as diferentes formas de organização da sociedade para atender demandas coletivas, uma concepção democrático-participativa que reveste a gestão pública da perspectiva cidadã.

A governança se encontra profundamente associada à gestão dos destinos turísticos (Anjos \& Kennell, 2019). A governança em destinos turísticos caracteriza-se como a descentralização do processo decisório, permitindo aos indivíduos participar dos processos inerentes à localidade (Fernandes \& Coriolano, 2015; Mtapuri \& Giampiccoli, 2020). Para González (2014), a governança turística auxilia a conciliar os conflitos de interesse, impulsionar a inovação social e fortalecer os atores mais frágeis. Contudo, as boas práticas de governança não garantem bons resultados, apenas facilitam a participação dos stakeholders no controle do turismo (Pechlaner, Beritelli, \& Volgger, 2015).

0 protagonismo da população local na gestão de bens e serviços turísticos destaca-se como uma das principais características do TBC (Fabrino et al., 2016), mas somente é possível atingi-lo com o envolvimento da comunidade (Mtapuri \& Giampiccoli, 2020). Entretanto, nem sempre a participação agirá em prol do TBC, pois ela poderá assumir variantes entre a manipulação e a autonomia do cidadão (Burgos \& Mertens, 2016), principalmente, quando os benefícios da atividade turística ficam restritos a um pequeno grupo de empreendedores da comunidade (Rogerson, 2014).

Desta forma, apesar do TBC possuir princípios como participação, integração, redes (Burgos \& Mertens, 2016; Fabrino et al., 2016; MTUR, 2010) relacionados à governança, esta não se desenvolve adequadamente nas comunidades, mesmo que reduza conflitos e promova a participação (Gómez et al., 2015; Villavicencio, Zamora, \& Pardo, 2016). Portanto, uma governança incipiente é um dos entraves para consolidação das iniciativas (Mielke \& Pegas, 2013). Logo, a aplicação do Modelo de Análise da Governança do TBC (MAG do TBC), proposto por Albuquerque (2016), configura-se como uma estratégia metodológica para operacionalizar a governança diante de sua polissemia.

\section{Modelo de Análise da Governança do TBC (MAG do TBC)}

Reconhecendo as conexões entre o TBC e a governança, o MAG do TBC define: participação, transparência e eficácia, como três dimensões analíticas da governança do TBC. As dimensões encontram-se justapostas, por isso, considera-se a intersecção dos pontos convergentes (Albuquerque, 2016). Cada dimensão é formada por elementos constituintes que exigem critérios de verificação para sua análise, conforme demonstra a figura 1.

A participação, primeira dimensão do modelo, compreende a integração entre a população e outros atores, auxiliando na transformação local e no processo de 
decisão (Albuquerque, 2016; Giampiccoli \& Saayman, 2018). A dimensão constitui-se de quatro elementos, a saber: (i) inclusão, relacionada à equidade, diversidade, justiça e poder compartilhado (Giampiccoli \& Saayman, 2018); (ii) da legitimidade, conferindo voz a todos na tomada de decisão (Burgos \& Mertens, 2017; Hall, 2011; Lockwood, 2010); (iii) do engajamento, que se relaciona à conectividade, ao envolvimento e à integração multinível, descentralizando a organização local; e (iv) do processo decisório, referente ao tipo de participação dos atores e nível de importância na tomada de decisão (Hall, 2011; Lockwood, 2010).

Figura 1 - MAG do TBC

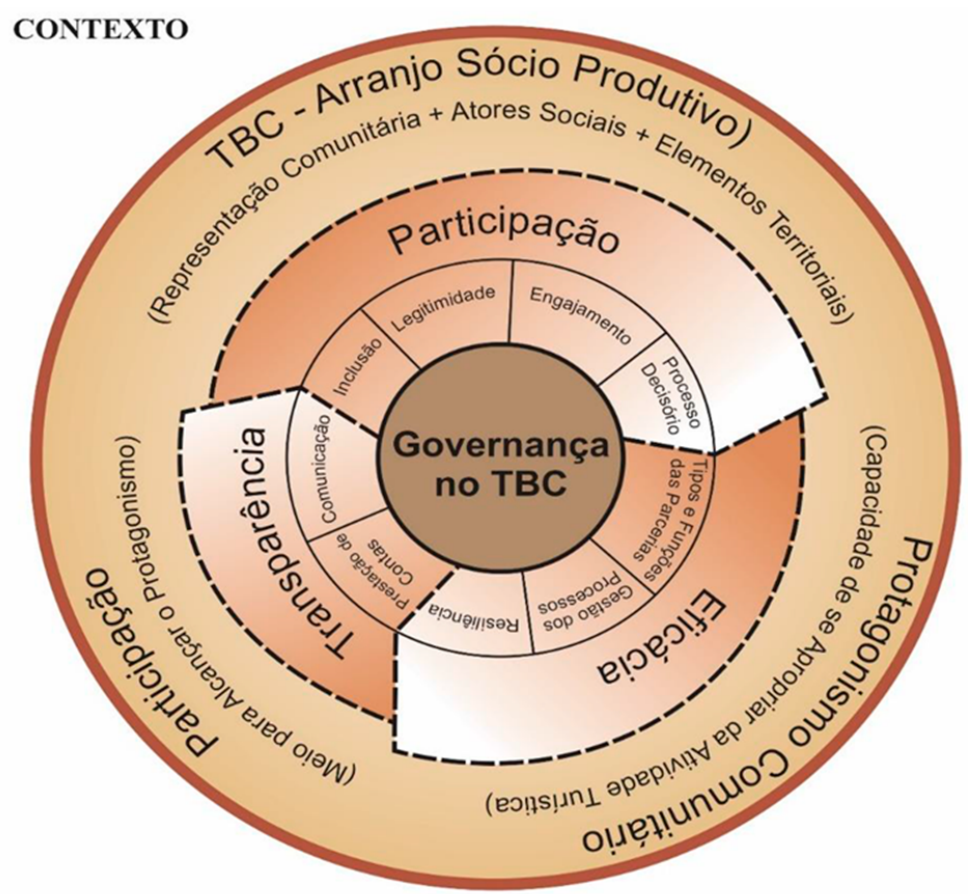

Fonte - Albuquerque, 2016, p. 263.

A segunda dimensão é a transparência, proporcionando confiança entre os atores na captação e destinação de recursos, conferindo responsabilidade aos envolvidos (Albuquerque, 2016). Os dois elementos constituintes são (i) a comunicação, promovendo a visibilidade dos processos, a clareza e a disponibilidade das informações (Lockwood, 2010); e (ii) a prestação de contas, ferramenta administrativa que possibilita sanções e incentivos diante do cumprimento ou não das ações planejadas (Albuquerque, 2016).

A última dimensão é a eficácia, contemplando o alcance dos objetivos em coerência com as necessidades e os pedidos dos atores (Albuquerque, 2016). Composta por três elementos, saber: (i) tipos e funções das parcerias, analisando as parcerias estratégicas, a implementação das decisões tomadas e o monitoramento da atividade (Giampiccoli \& Saayman, 2018); (ii) gestão dos processos, apresentando-se como um indicador de eficácia em arranjos produtivos com múltiplos atores (Albuquerque, 2016); e (iii) resiliência, responsável pelo enfrentamento das adversidades, superando desafios e mudanças e zelando pelo compartilhamento de experiências (Lockwood, 2010). A investigação destas dimensões possibilitou a análise da governança nas comunidades estudadas. 


\section{METODOLOGIA}

A presente investigação caracteriza-se como uma pesquisa qualitativa, descritiva e explicativa, na qual, analisou-se a governança através da aplicação do MAG do TBC, avaliando as três dimensões do modelo participação, transparência e eficácia, adotadas como construtos desta pesquisa, conforme demonstra a figura 2 .

Figura 2 - Desenho da pesquisa

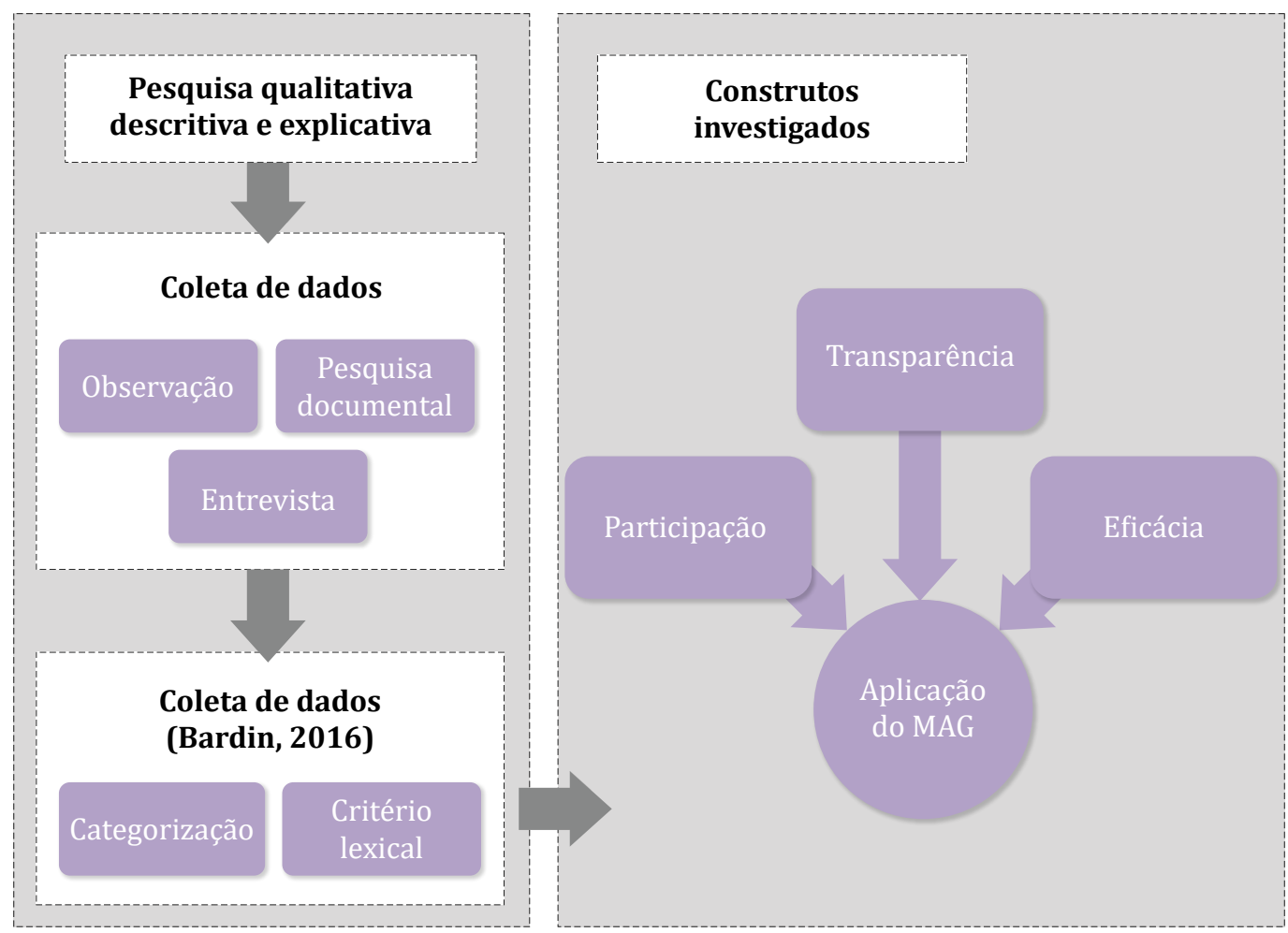

Fonte - Elaborado pelas autoras, 2019.

A coleta de dados foi realizada em etapas consecutivas através da observação, pesquisa documental e entrevistas semiestruturadas, garantindo confiabilidade e validade por meio da triangulação dos dados (Creswell, 2016).

A observação do tipo não participante ocorreu de maneira assistemática e sistemática. A observação assistemática esteve presente desde o primeiro contato de uma das pesquisadoras com as comunidades em 2015, a fim de compreender como o fenômeno TBC se inseriu no contexto da localidade e os benefícios trazidos oriundo da atividade. A partir de 2017, este contato foi intensificado na busca de um olhar mais apurado sobre a governança das comunidades, guiando-se pelos construtos adotados nesta investigação: participação, transparência e eficácia. No decorrer da pesquisa, utilizou-se a observação sistemática nos seguintes eventos: "O Fantástico Mundo do Turismo Criativo" (setembro/2017); "Recife do Coração" (setembro/2017); "AquaSESC" (outubro/2017); "Encontro das Marisqueiras de Nossa Senhora do Ó - Ipojuca/PE” (novembro/2017); "Dia Mundial da Criatividade" (abril/2018); e o "XV Encontro Nacional de Turismo de Base Local" (setembro/2018). Durante e após os eventos, aspectos relacionados ao objetivo da pesquisa, situações peculiares e impressões das pesquisadoras foram registradas conforme o construto correspondente em um diário de campo. 
A pesquisa documental consistiu em buscas nos sites e redes sociais das ONGs que coordenam ações na Ilha de Deus e na Bomba do Hemetério permitindo formar um corpus de materiais orais e audiovisuais elencados no quadro 1.

Quadro 1 - Corpus da pesquisa documental sobre governança nas comunidades pesquisadas

\begin{tabular}{|c|c|c|}
\hline Materiais & Tipo & Identificação \\
\hline Depoimento do Coordenador da Universidart & Audiovisual & D1 \\
\hline Depoimento de integrante da Rádio Seu Hemetério & Audiovisual & D2 \\
\hline $\begin{array}{l}\text { Depoimento da Presidente da Cooperativa de Mulheres Artesãs } \\
\text { Saber Viver }\end{array}$ & Oral & D3 \\
\hline Depoimento do Presidente da Ação Comunitária Caranguejo Uçá & Audiovisual & D4 \\
\hline
\end{tabular}

Fonte - Pesquisa Documental, 2018.

A entrevista semiestruturada foi escolhida como técnica de coleta pela sua adaptabilidade, pois permite investigar mais profundamente os motivos e os sentimentos envolvidos (Bell, 2008). Assim, foram entrevistados quatro stakeholders da Bomba do Hemetério e da Ilha de Deus, são eles: o Coordenador de Projetos da ONG Saber Viver que capitaneia a iniciativa de TBC na Ilha de Deus, o Representante da ONG Universidart que coordenava a iniciativa de TBC da Bomba do Hemetério e dois cofundadores da Rede Nacional de Turismo Criativo (RECRIA). A amostra caracterizou-se como intencional, pois foram escolhidos atores que realizam a gestão do TBC nas comunidades estudadas. Assim, formou-se um corpus de materiais orais oriundos da pesquisa de campo, conforme demonstra o quadro 2 .

Quadro 2 - Corpus das entrevistas realizadas

\begin{tabular}{|l|l|c|}
\hline \multicolumn{1}{|c|}{ Materiais } & Tipo & Identificação \\
\hline $\begin{array}{l}\text { Entrevista Representante da ONG Universidart da Bomba do } \\
\text { Hemetério }\end{array}$ & Oral & E1 \\
\hline \begin{tabular}{l} 
Entrevista Coordenador de Projetos da ONG Saber Viver da Ilha de Deus \\
\hline $\begin{array}{l}\text { Entrevista Cofundador da Rede Nacional de Turismo Criativo } \\
\text { (RECRIA) A }\end{array}$
\end{tabular} & Oral & E2 \\
\hline $\begin{array}{l}\text { Entrevista Cofundador da Rede Nacional de Turismo Criativo } \\
\text { (RECRIA) B }\end{array}$ & Eral & E3 \\
\hline
\end{tabular}

Fonte - Pesquisa de Campo, 2019.

Todas as entrevistas foram realizadas presencialmente nas comunidades, no período de 11/03/2019 a 05/04/2019, tendo sido gravadas com a devida autorização dos entrevistados. As transcrições foram feitas com o auxílio da ferramenta "digitação por voz" da plataforma Google Docs e posteriormente revisadas pelas pesquisadoras.

A Análise de Conteúdo (AC) foi escolhida para o tratamento analítico dos dados. A perspectiva utilizada foi a de Bardin (2016), em sua técnica categorial, que prevê três fases fundamentais: a pré-análise, exploração do material e tratamento dos resultados: a inferência e a interpretação. A categorização seguiu o critério léxico, na qual as palavras se classificam por seu sentido, emparelhando 
sinônimos e palavras de sentidos próximos (Bardin, 2016), sendo criadas de maneiras apriorísticas. Os elementos constituintes do MAG do TBC foram utilizados como categorias, conforme demonstra o quadro 3.

Quadro 3 - Construtos, categorias e autores de referência

\begin{tabular}{|c|c|c|}
\hline Construtos & Categorias & Autores de Referência \\
\hline \multirow{4}{*}{ Participação } & Inclusão & Giampiccoli e Saayman (2018) \\
\hline & Legitimidade & $\begin{array}{l}\text { Burgos e Mertens (2017); Hall (2011); } \\
\text { Lockwood (2010) }\end{array}$ \\
\hline & Engajamento & Hall (2011); Lockwood (2010) \\
\hline & Processo Decisório & Hall (2011) \\
\hline \multirow{2}{*}{ Transparência } & Prestação de Contas & Albuquerque (2016) \\
\hline & Comunicação & Lockwood (2010) \\
\hline \multirow{3}{*}{ Eficácia } & Tipos e Funções de Parcerias & $\begin{array}{l}\text { Burgos e Mertens (2017); Giampiccoli e } \\
\text { Saayman (2018) }\end{array}$ \\
\hline & Gestão de Processos & Albuquerque (2016) \\
\hline & Resiliência & Lockwood (2010) \\
\hline
\end{tabular}

Na pré-análise, procedeu-se à leitura flutuante do material coletado: diário de campo com dados obtidos da observação, corpus da pesquisa documental e transcrições das entrevistas. Durante a exploração do material, tomando por base as categorias analíticas previamente estabelecidas, foram feitos recortes das falas dos entrevistados, das anotações no diário de campo bem como dos documentos, codificando o material em um quadro, para facilitar a percepção da saturação dos dados. Já no tratamento dos resultados, realizou-se manualmente o cruzamento das informações a partir das categorias, fazendo emergir situações não tão perceptíveis no contexto, possibilitando as discussões e inferências. Não foi utilizado nenhum software de análise de dados qualitativos.

Diante do exposto, percebe-se a extensão dos procedimentos metodológicos adotados, evidenciando a necessidade de dividi-los conforme as dimensões do MAG do TBC para melhor organizar e interpretar a profusão de dados relacionados à dificuldade de consolidação das iniciativas de TBC recifenses no mercado turístico. Desta forma, obtiveram-se os subsídios necessários para a investigação do problema de pesquisa.

\section{RESULTADOS E DISCUSSÃO}

\section{As iniciativas recifenses de TBC: Bomba do Hemetério e Ilha de Deus}

A Bomba do Hemetério integra um complexo de bairros populares situados na Zona Norte do Recife. A comunidade apresenta uma grande quantidade de manifestações artístico-culturais de matrizes africanas e indígenas, ultrapassando 60 grupos. Estes grupos são responsáveis por mais da metade dos desfiles e apresentações do carnaval pernambucano (Leão \& Pereira, 2018). Devido ao grande 
potencial cultural da Bomba do Hemetério, no ano de 2011, foi criado o Programa Bombando Cidadani ${ }^{1}$ pelo Instituto de Assessoria para o Desenvolvimento Humano (IADH) e Instituto Walmart em parceria com o MTUR e o SEBRAE-PE, dentro do qual foi elaborado o Circuito Turístico Bomba Cultural, composto pelos roteiros: "Conhecendo o Território", "Cultura e Tradição", "Roteiro das Artes" e "BombÁfrica", visando a atender aos turistas durante a Copa do Mundo de 2014.

As ações voltadas à cultura e ao turismo deveriam ser gerenciadas pela ONG Universidart, fundada em 2001 e reestruturada durante o mencionado programa, porém, a mesma encontra-se desativada, pois não obteve êxito em gerenciar as ações planejadas. No momento, destacam-se indivíduos, empresários locais e grupos culturais que ofertam produtos turísticos na região. A adesão à Rede Nacional de Turismo Criativo (RECRIA), fundada em setembro de 2017, visando estimular o turismo criativo no território nacional, possibilitou maior entrosamento entre estes atores, que apesar da pouca articulação dentro do território, buscam tomar decisões coletivamente através da rede.

Já a Ilha de Deus, anteriormente chamada de "Ilha sem Deus", era uma comunidade de palafitas na zona sul do Recife, que sobrevivia da pesca e da coleta de bivalves no ambiente estuarino. A partir de 2007, passou por um projeto de urbanização em duas partes: o Projeto Físico de Urbanização e o Projeto de Sustentabilidade de Pós-ocupação (Moraes \& Marques, 2017), realizado por órgãos governamentais do estado e pela comunidade.

O projeto do TBC surgiu no ano de 2011, como uma alternativa de renda às atividades primárias da ilha, a partir de um projeto da ONG Saber Viver, porém, a ilha já tinha a tradição de receber voluntários desde a década de 1980. A Ilha de Deus oferta cinco produtos turísticos: "Férias Voluntárias", "Intercâmbio Internacional", "Tour Pedagógico", "Passeio de Catamarã", e a vivência "Cozinhando com Negra Linda", estas ações são desenvolvidas pelos empreendedores sociais, jovens da comunidade que usufruíram dos projetos sociais da ONG quando crianças e continuam vinculados à Saber Viver. A Ilha de Deus também integra a Rede Nacional de Turismo Criativo (RECRIA).

\section{Resultados da aplicação do MAG do TBC}

Na dimensão da participação, investigou-se a categoria inclusão para avaliar o interesse dos envolvidos e a abertura à participação. Quanto ao interesse dos envolvidos, evidenciou-se o cuidado em inserir todos no processo como se percebeu no extrato de fala do representante da Ilha de Deus: "a gente se reúne frequentemente através de ata, de reunião e etc., para discutir o que nós vamos fazer ou o que nós já fizemos para analisar se tá (sic) certo ou errado" (E2). Já a Bomba do Hemetério, apresentou maior dependência externa, antes Walmart, IADH e SEBRAE e depois RECRIA, para as decisões relacionadas ao TBC como fica explícito no recorte seguinte: "nós temos um grupo de Whatsapp, chamado

1. Programa de apoio ao desenvolvimento local por meio de mobilização, organização comunitária e formação de lideranças locais tendo como eixos de atuação: Geração de Renda, Saúde e Meio Ambiente, Educação, Juventude e Desenvolvimento Cultural, realizado na Bomba do Hemetério no período de 2008 a 2012. Mais informações em: http://www.iadh.org.br/tag/bombando-cidadania/. 
RECRIA, que hoje a RECRIA é quem está fazendo o movimento propriamente dito do turismo de base comunitária dentro dos territórios" (E1).

Para a RECRIA, esta representatividade dos associados se dá de maneira mais democrática, os temas discutidos podem surgir a partir do Núcleo Gestor, mas mantendo um canal aberto para debater quaisquer temas oriundos das comunidades, demonstrando maior inclusão entre os atores. Um dos gestores da rede explicou que a ideia inicial era manter a filiação aberta a todos, mas posteriormente resolveram estabelecer critérios.

Hoje, a pessoa precisa ser produtora de turismo criativo. Precisa ser empreendedor de turismo criativo ou associado diretamente (...). A gente percebeu que para a rede funcionar, tinha que ser bom para todo mundo e para a rede ser nutrida precisa ter ida e volta (E3).

As comunidades são abertas à participação de novos atores que demonstrem interesse pelo TBC, como se verificou no excerto: "a gente é sempre aberto. A gente não só utiliza esses grupos como o Maracatu Raízes de Pai Adão, do Boi Malabá, como também dá oportunidade a todos os grupos que queiram participar" (E1). Na Ilha de Deus, essa abertura à participação é vista como uma forma de integrar as ações dos atores com a comunidade, como afirma a seguinte fala: "aqui é o meu trabalho (...), eu sou autônoma, dona do meu horário (...) sai da zona de conforto, consegui carteira de artesão, participei da Fenearte (...) com o dinheiro da Saber Viver" (D3). Entretanto, esse sentimento de inclusão não é percebido por toda a comunidade, podendo representar conflitos internos como estudaram Blackstock (2005) e Burgos e Mertens (2016). A fala do Coordenador da ACCU apresenta essa crítica ao afirmar: "A nossa ideia era fazer diferente, era romper com essa ideia de liderança comunitária, de que as pessoas tinham que ter representantes e tal, ao invés de se auto representarem em grupos organizados" (D4).

Esse aspecto também fica evidenciado na fala do representante da ONG Saber Viver: "Nós trabalhamos para toda a comunidade, é diferente, mas toda a comunidade não aceita que tenha alguém representando. Ela é representada por ela mesma, isso é um direito deles" (E2). Na Bomba do Hemetério, durante o Programa Bombando Cidadania, a tentativa de incluir a comunidade transparecia nos discursos de seus representantes: "hoje, a Bomba está nesse desenvolvimento, não é um só que tem a ideia, ou programa que tem a ideia, mas a comunidade está passando a ter a ideia também. Nós nos juntamos e chegamos aonde nós queremos" (D2), ou ainda "não adianta a gente querer desenvolver a comunidade se a gente não se envolve, e se não contamina as outras pessoas ao nosso redor" (D1), estes ideais de integração, no quais se fortalecem os elos comunitários são bases para uma boa governança. 0 quadro 4 sintetiza os critérios de análise e de verificação da categoria inclusão e os achados nas duas comunidades analisadas.

Desta forma, percebeu-se a inclusão presente no discurso destes atores para garantir equidade e poder compartilhado, observou-se que embora não representem uma totalidade, há um entendimento dos atores sobre a necessidade de proporcionar o acesso de todos os envolvidos nas tomadas de decisão sobre a atividade, corroborando com as ideias de Giampiccoli e Saayman (2018). 
Quadro 4 - Análise da categoria "inclusão" nas comunidades pesquisadas

\begin{tabular}{|c|c|c|c|c|}
\hline $\begin{array}{l}\text { Critério de } \\
\text { Análise }\end{array}$ & $\begin{array}{l}\text { Critério de } \\
\text { Verificação }\end{array}$ & \multicolumn{2}{|c|}{ Ilha de Deus } & $\begin{array}{l}\text { Bomba do } \\
\text { Hemetério }\end{array}$ \\
\hline \multirow{3}{*}{$\begin{array}{l}\text { Composição } \\
\text { dos atores }\end{array}$} & $\begin{array}{l}\text { Caracterização dos } \\
\text { atores sociais }\end{array}$ & $\begin{array}{l}\text { ONG } \\
\text { Saber } \\
\text { Viver }\end{array}$ & $\begin{array}{l}\text { Empreendedores } \\
\text { Sociais }\end{array}$ & Operadores Locais \\
\hline & Esferas de atuação & $\begin{array}{l}\text { Terceiro } \\
\text { Setor }\end{array}$ & Mercado & Sociedade civil \\
\hline & $\begin{array}{l}\text { Formas de } \\
\text { representação } \\
\text { comunitária }\end{array}$ & \multicolumn{2}{|c|}{ Diretoria da ONG } & Não há presença \\
\hline \multirow[b]{2}{*}{$\begin{array}{l}\text { Interesses dos } \\
\text { envolvidos }\end{array}$} & $\begin{array}{l}\text { Surgimento dos temas } \\
\text { para discussões }\end{array}$ & \multicolumn{2}{|c|}{ Top down } & $\begin{array}{l}\text { Top down ou } \\
\text { Bottom up }\end{array}$ \\
\hline & $\begin{array}{l}\text { Representação } \\
\text { dos interesses dos } \\
\text { participantes }\end{array}$ & \multicolumn{2}{|c|}{$\begin{array}{l}\text { Decisão de pautas conjuntas } \\
\text { para as discussões }\end{array}$} & $\begin{array}{l}\text { Os operadores } \\
\text { locais buscam } \\
\text { decidir } \\
\text { conjuntamente }\end{array}$ \\
\hline \multirow{3}{*}{$\begin{array}{l}\text { Abertura à } \\
\text { participação }\end{array}$} & $\begin{array}{l}\text { Critérios para } \\
\text { participação }\end{array}$ & \multicolumn{2}{|c|}{$\begin{array}{l}\text { Entender o aspecto social da } \\
\text { atividade (ganhos financeiros } \\
\text { demoram) }\end{array}$} & Não há critérios \\
\hline & $\begin{array}{l}\text { Situações que } \\
\text { impedem a } \\
\text { participação }\end{array}$ & \multicolumn{2}{|c|}{ Não impõe restrições } & $\begin{array}{l}\text { Relacionados à } \\
\text { integridade do } \\
\text { indivíduo }\end{array}$ \\
\hline & $\begin{array}{l}\text { Metodologias } \\
\text { que promovam a } \\
\text { participação }\end{array}$ & \multicolumn{2}{|c|}{ Não são utilizadas } & Não são utilizadas \\
\hline
\end{tabular}

Fonte - Elaborado pelas autoras, 2019.

A segunda categoria analisada foi a legitimidade, destacando-se o exercício da liderança, observou-se que a ONG Saber Viver possui representantes escolhidos por votação com mandato por tempo determinado como se observou em "hoje, é de 5 em 5 anos, você faz uma nova eleição. Pela nova regulamentação, a diretoria pode ser renovada ou não, as pessoas podem participar" (E2). Já a Bomba do Hemetério não dispõe de representantes que respondam pela totalidade, mas de indivíduos que promovem e comercializam a atividade isoladamente e tomam decisões coletivamente. Os atores não investem diretamente na formação de novos líderes, mas na Ilha de Deus observou-se que a diretoria da ONG Saber Viver é composta em sua maioria por jovens, que cresceram participando ativamente das ações desenvolvidas pela ONG.

Sobre essa liderança democrática, a cofundadora da RECRIA explicou que apesar de tentar manter a rede mais democrática possível, na qual todos pudessem responder por qualquer situação provocou uma inoperância, assim, eles têm procurado uma nova forma de organização.

(...) quando a RECRIA começou a gente trabalhou num conceito de que todo mundo podia fazer tudo, que todo mundo era responsável por tudo, era tudo de fato muito democrático, mas isso gerou uma lentidão grande (E4). 
A síntese dos critérios investigados e os achados da categoria legitimação encontra-se no quadro 5 abaixo.

Quadro 5 - Análise da categoria "legitimidade" nas comunidades pesquisadas

\begin{tabular}{|c|c|c|c|}
\hline $\begin{array}{l}\text { Critérios de } \\
\text { Análise }\end{array}$ & $\begin{array}{l}\text { Critério de } \\
\text { Verificação }\end{array}$ & Ilha de Deus & Bomba do Hemetério \\
\hline \multirow{4}{*}{$\begin{array}{l}\text { Exercício da } \\
\text { Liderança }\end{array}$} & $\begin{array}{l}\text { Forma de escolha dos } \\
\text { representantes }\end{array}$ & Votação & $\begin{array}{l}\text { Não há representantes } \\
\text { escolhidos }\end{array}$ \\
\hline & $\begin{array}{l}\text { Critérios de } \\
\text { rotatividade no } \\
\text { exercício da liderança }\end{array}$ & A cada 5 anos & Ausência de liderança \\
\hline & $\begin{array}{l}\text { Ações para a } \\
\text { formação de } \\
\text { lideranças }\end{array}$ & $\begin{array}{l}\text { Formação continuadas, } \\
\text { por isso, } 80 \% \text { da diretoria } \\
\text { é composta por jovens } \\
\text { oriundos deste processo }\end{array}$ & $\begin{array}{l}\text { Não há formações para } \\
\text { futuros líderes }\end{array}$ \\
\hline & $\begin{array}{l}\text { Aparatos normativos } \\
\text { que regem as relações } \\
\text { entre os atores }\end{array}$ & Estatuto Social & Não possui \\
\hline \multirow{3}{*}{$\begin{array}{l}\text { Congruências } \\
\text { entre objetivos } \\
\text { e ações }\end{array}$} & $\begin{array}{l}\text { Comparação } \\
\text { entre decisões } \\
\text { tomadas e objetivos } \\
\text { estabelecidos }\end{array}$ & $\begin{array}{l}\text { Metas são estabelecidas e } \\
\text { buscam manter este foco }\end{array}$ & $\begin{array}{l}\text { Metas são estabelecidas } \\
\text { e buscam manter este } \\
\text { foco }\end{array}$ \\
\hline & $\begin{array}{l}\text { Decisões sem o } \\
\text { conhecimento e } \\
\text { participação dos } \\
\text { participantes }\end{array}$ & $\begin{array}{l}\text { Somente a diretoria } \\
\text { participa das decisões }\end{array}$ & $\begin{array}{l}\text { Nem sempre são } \\
\text { decisões conjuntas }\end{array}$ \\
\hline & $\begin{array}{l}\text { Situações em que } \\
\text { decisões tomadas } \\
\text { coletivamente não } \\
\text { foram implantadas }\end{array}$ & $\begin{array}{l}\text { Existem, mas são } \\
\text { esparsas e justificadas }\end{array}$ & Comumente \\
\hline $\begin{array}{l}\text { Integridade e } \\
\text { compromisso }\end{array}$ & $\begin{array}{l}\text { Código de conduta ou } \\
\text { de ética }\end{array}$ & Existe & Ausente \\
\hline
\end{tabular}

Fonte - Elaborado pelas autoras, 2019.

Diante do exposto, percebeu-se a tentativa de privilegiar formas de lideranças mais democráticas, porém para impedir a morosidade ou inoperância dos processos do TBC, decisões táticas e operacionais são tomadas pelos integrantes de diretorias, conselhos e núcleos gestores. Entretanto, estes indivíduos são democraticamente eleitos conferindo-lhes legitimidade nas decisões tomadas, ratificando os estudos de Burgos e Mertens (2017) e Hall (2011).

0 engajamento foi a terceira categoria investigada, destacando-se a integração entre os atores, comumente retratadas por ações colaborativas e solidárias entre os participantes, ou seja, investigou-se o sentimento de coletividade entre os atores conforme retrata Albuquerque (2016). Entretanto, ao examinar as relações entre estes atores, percebem-se características distintas para cada um deles. A ONG Saber Viver apresentou uma estrutura hierárquica, enquanto na Bomba do Hemetério, as relações tendem à horizontalidade. A cooperação entre os atores foi investigada através da gestão de conflitos. 0 diálogo figurou como o principal mecanismo para gerir conflitos advindos do TBC. Na visão dos 
administradores da Saber Viver, os conflitos existem devido à heterogeneidade das pessoas representadas: "não é conflito, é natural. Em nenhum lugar do mundo, uma instituição ou uma pessoa é unânime, principalmente, dentro de uma comunidade" (E1). Desta forma, o quadro 6 resume os critérios investigados da categoria engajamento.

Quadro 6 - Análise da categoria "engajamento" nas comunidades pesquisadas

\begin{tabular}{|c|c|c|c|}
\hline $\begin{array}{c}\text { Critérios de } \\
\text { Análise }\end{array}$ & $\begin{array}{l}\text { Critério de } \\
\text { Verificação }\end{array}$ & Ilha de Deus & Bomba do Hemetério \\
\hline \multirow[t]{2}{*}{ Integração } & $\begin{array}{l}\text { Ações colaborativas } \\
\text { e solidárias entre os } \\
\text { membros }\end{array}$ & Frequentemente & $\begin{array}{l}\text { Existem, mas são } \\
\text { esparsas }\end{array}$ \\
\hline & $\begin{array}{l}\text { Caracterização das } \\
\text { relações }\end{array}$ & Vertical & Horizontal (tendência) \\
\hline \multirow{3}{*}{$\begin{array}{l}\text { Cooperação } \\
\text { entre os } \\
\text { atores }\end{array}$} & $\begin{array}{l}\text { Mecanismos para } \\
\text { gestão de conflitos }\end{array}$ & Apostam no diálogo & Não há mecanismos \\
\hline & $\begin{array}{l}\text { Reconhecimento do } \\
\text { papel e importância } \\
\text { de cada participante }\end{array}$ & Existe & Existe \\
\hline & $\begin{array}{l}\text { Existência de } \\
\text { promoção do } \\
\text { envolvimento dos } \\
\text { participantes }\end{array}$ & $\begin{array}{l}\text { Sim, os participantes } \\
\text { procuram manter uma } \\
\text { relação próxima e se } \\
\text { reunirem sempre }\end{array}$ & $\begin{array}{l}\text { Sim, mas buscam o } \\
\text { envolvimento por } \\
\text { aplicativos de chat no } \\
\text { celular }\end{array}$ \\
\hline
\end{tabular}

Fonte - Elaborado pelas autoras, 2019.

A partir da análise, verificou-se engajamento dos atores que operam o TBC nas comunidades, permitindo a integração multinível dos envolvidos, levando a uma descentralização do planejamento e da operação da atividade turística, como indicaram Hall (2011) e Lockwood (2010).

A última categoria da dimensão de participação foi o processo decisório, tipificando a participação dos atores e avaliando o nível de importância da tomada de decisão. Quanto ao tipo de participação, a Bomba do Hemetério aproximou-se da cogestão, na qual a participação é compartilhada. Já na Ilha de Deus, a participação ocorreu no grau de delegação, havendo autonomia dos empreendedores sociais em relação à Saber Viver. Quanto ao nível de importância, embora todos os atores encontram-se no nível máximo, postula-se uma crítica ao MAG do TBC. Observou-se no contexto estudado que os atores podem desenvolver uma ação de um nível mais alto sem ter passado pelos níveis anteriores. Portanto, estes níveis não se apresentam, necessariamente, numa escalada crescente, conforme sintetiza o quadro 7.

Quadro 7 - Análise da categoria "processo decisório" nas comunidades pesquisadas

\begin{tabular}{|c|l|l|l|}
\hline Critério de Análise & \multicolumn{1}{|c|}{ Critério de Verificação } & Ilha de Deus & Bomba do Hemetério \\
\hline Tipos de participação & $\begin{array}{l}\text { Caracterização dos tipos de } \\
\text { participação }\end{array}$ & Delegação & Cogestão \\
\hline Nível de importância & $\begin{array}{l}\text { Caracterização do nível de } \\
\text { participação no processo de } \\
\text { tomada de decisão }\end{array}$ & Nível 6 & Nível 6 \\
\hline
\end{tabular}

Fonte - Elaborada pelas autoras, 2019. 
Na dimensão da transparência, a primeira categoria foi comunicação, na qual se observou existir um fluxo de informações constantes, embora deficitário em alguns aspectos. Na Ilha de Deus, a comunicação se configura como um elemento forte do TBC como explicitado por um dos entrevistados: "Nós temos muito forte isso hoje. Temos o Facebook, temos o site, temos o Instagram. Nós temos uma rádio comunitária aqui do lado, do Edson. Tudo isso funciona, mas temos uma coisa que funciona mais aqui que é o boca a boca" (E2). Na Bomba do Hemetério, as informações sobre o desempenho do TBC são disponibilizadas isoladamente por cada ator, como demonstra o trecho da fala de seu representante: "dentro da Bomba do Hemetério, a nossa comunicação é mais via rede social, Facebook, mas de forma não institucionalizada" (E1).

A RECRIA observou que a comunicação da rede ainda não se encontra num formato desejável, contratando uma assessoria de comunicação, pois ela estava sendo desenvolvida de forma muito amadora, como explicou a gestora: "agora, a gente contratou também uma assessoria de comunicação, que vai ficar mais fácil, pois cada atividade que a gente faz gera uma notícia, gera um fato" (E3).

Os aspectos indicados pela RECRIA se referem à adequação do processo enunciativo para incluir todos os seus associados, justamente elementos observados na qualidade da informação. Destaca-se ainda que embora a Ilha de Deus possua atas, balancetes financeiros, entre outros, resguarda o acesso a estes documentos à diretoria: "Não, esses são documentos ficam dentro da ONG, tá? (sic)" (E2). 0 quadro 8 resume todos os critérios investigados.

Quadro 8 - Análise da categoria "comunicação" nas comunidades pesquisadas

\begin{tabular}{|c|c|c|c|}
\hline $\begin{array}{l}\text { Critério de } \\
\text { Análise }\end{array}$ & $\begin{array}{l}\text { Critério de } \\
\text { Verificação }\end{array}$ & Ilha de Deus & Bomba do Hemetério \\
\hline $\begin{array}{l}\text { Disponibilidade } \\
\text { de informações }\end{array}$ & $\begin{array}{l}\text { Canais de difusão da } \\
\text { informação }\end{array}$ & $\begin{array}{l}\text { Mídias sociais da ONG e } \\
\text { rádio comunitária }\end{array}$ & $\begin{array}{l}\text { Mídias sociais de cada } \\
\text { grupo cultural }\end{array}$ \\
\hline \multirow{2}{*}{$\begin{array}{l}\text { Qualidade da } \\
\text { informação }\end{array}$} & $\begin{array}{l}\text { Linguagem adequada } \\
\text { na comunicação }\end{array}$ & Existe & Existe \\
\hline & $\begin{array}{l}\text { Relevância das } \\
\text { informações } \\
\text { disponíveis }\end{array}$ & $\begin{array}{l}\text { Informações necessárias } \\
\text { à gestão, e divulgação } \\
\text { das ações realizadas }\end{array}$ & Não dispõe \\
\hline $\begin{array}{l}\text { Tipo de } \\
\text { informações }\end{array}$ & $\begin{array}{l}\text { Tipos de documentos } \\
\text { disponibilizados aos } \\
\text { participantes }\end{array}$ & $\begin{array}{l}\text { Somente o estatuto, } \\
\text { demais documentos } \\
\text { são considerados } \\
\text { exclusivos da ONG }\end{array}$ & $\begin{array}{l}\text { Não há produção de } \\
\text { documentos }\end{array}$ \\
\hline
\end{tabular}

Fonte - Elaborado pelas autoras, 2019.

A partir do exposto, observou-se que a comunicação apesar de existente, desenvolve-se de forma embrionária, sendo formulada pelos próprios atores e necessitando de um suporte mais profissional. Lockwood (2010) defende um fluxo das informações livre, permitindo visibilidade, clareza e disponibilidade das mesmas, porém entre os atores somente a RECRIA possui esta visão, e ainda não conseguiu estruturar de maneira eficiente esta área.

Outra categoria foi prestação de contas. No tocante aos relatórios financeiros e contábeis, os atores conseguem executá-los de maneira razoável. Quando se considera o feedback das ações e projetos executados, percebeu-se que as reuniões 
são utilizadas para compreender e propor ações corretivas ao desempenho destas estruturas, havendo respeito às decisões tomadas coletivamente, mas não havendo muitos registros destes acompanhamentos. Portanto, a prestação de contas exige maior atenção dos atores nos métodos e nas ferramentas utilizadas para atingir uma boa governança. Caso contrário, a categoria não irá conferir transparência à gestão, além de auxiliar na obtenção das metas estabelecidas, como descreveu Albuquerque (2016), conforme demonstrado no quadro 9.

Quadro 9 - Análise da categoria "prestação de contas" nas comunidades pesquisadas

\begin{tabular}{|c|c|c|c|}
\hline Critério de Análise & Critério de Verificação & Ilha de Deus & Bomba do Hemetério \\
\hline \multirow{2}{*}{$\begin{array}{l}\text { Mecanismos de } \\
\text { prestação de contas }\end{array}$} & $\begin{array}{l}\text { Mecanismos de prestação } \\
\text { de contas }\end{array}$ & $\begin{array}{l}\text { Há balancetes } \\
\text { financeiros e } \\
\text { avaliações }\end{array}$ & Balancete financeiro \\
\hline & $\begin{array}{l}\text { Ações para a formação } \\
\text { dos participantes em } \\
\text { atividades relacionadas a } \\
\text { este processo }\end{array}$ & Não existe & Não existe \\
\hline \multirow[t]{2}{*}{ Ações Corretivas } & $\begin{array}{l}\text { Situações nas quais } \\
\text { ações corretivas foram } \\
\text { incorporadas como } \\
\text { resultado da avaliação } \\
\text { de desempenho }\end{array}$ & $\begin{array}{l}\text { Após a execução } \\
\text { dos projetos }\end{array}$ & Existe \\
\hline & $\begin{array}{l}\text { Respeito às decisões e } \\
\text { à sua implementação }\end{array}$ & Existe & Existe \\
\hline $\begin{array}{l}\text { Respeito às } \\
\text { decisões }\end{array}$ & $\begin{array}{l}\text { Percepção dos } \\
\text { participantes quanto } \\
\text { a este respeito }\end{array}$ & Existe & Existe \\
\hline
\end{tabular}

Fonte - Elaborado pelas autoras, 2019.

A última dimensão é a eficácia. A categoria tipos e funções de parcerias foi analisada através da caracterização das parcerias. A ONG Saber Viver conseguiu a visibilidade da atividade turística através da existência de parceiros, conforme destacou o seu representante:

No empreendedorismo, nós temos a RECRIA (...), o Catamaran Tours, o Recife Convention Bureau, (...), o SEBRAE, que é um parceiro também na área comercial e social, que qualifica e dá cursos de qualificação para o nosso pessoal na área de empreendedorismo, e também hoje, a Abrasel, que nós estamos sendo filiados agora (E2).

0 Programa Bombando Cidadania desenvolvido na Bomba do Hemetério, com o suporte do Instituto Walmart e do IADH, impulsionou as ações de TBC na comunidade, e esta, posteriormente, atraiu novos parceiros como o SEBRAE e a Prefeitura da Cidade do Recife, como explicado no trecho seguinte: “(...) enfim, a gente tem vários parceiros, hoje o SEBRAE é um dos nossos parceiros, IADH, desde o início, Aliança Empreendedora, Instituto Aliança" (E1). Logo, as parcerias são elementos essenciais à consolidação da atividade turística, além de contribuírem para a governança, como demonstrou Albuquerque (2016). 
A RECRIA tem entre as suas principais funções promover articulações com os atuais e novos parceiros para conseguir melhor qualificação dos produtos e serviços ofertados, capacitação dos atores envolvidos e promoção dos destinos. No entanto, na Bomba percebe-se uma dependência grande da subvenção de parceiros como a Prefeitura da Cidade do Recife para promover a continuidade dos seus projetos, revelando uma dependência externa. Tais aspectos foram sintetizados no quadro 10.

Quadro 10 - Análise da categoria "tipos e funções de parcerias" nas comunidades pesquisadas

\begin{tabular}{|c|c|c|c|}
\hline $\begin{array}{l}\text { Critério de } \\
\text { Análise }\end{array}$ & Critério de Verificação & Ilha de Deus & $\begin{array}{l}\text { Bomba do } \\
\text { Hemetério }\end{array}$ \\
\hline \multirow{10}{*}{$\begin{array}{l}\text { Caracterização } \\
\text { das parcerias }\end{array}$} & $\begin{array}{l}\text { Articulações com outras } \\
\text { experiências para } \\
\text { fortalecimento de uma rede }\end{array}$ & RECRIA & RECRIA \\
\hline & $\begin{array}{l}\text { Articulações entre atores } \\
\text { sociais para captação de } \\
\text { recursos }\end{array}$ & Existe & Existe \\
\hline & $\begin{array}{l}\text { Presença de agências de } \\
\text { desenvolvimento, parceiros } \\
\text { comerciais e outros. }\end{array}$ & Existe & Existe \\
\hline & $\begin{array}{l}\text { Quantitativo de recursos } \\
\text { captados (por ano) para } \\
\text { desenvolvimento }\end{array}$ & $\begin{array}{l}\text { Subvenção da } \\
\text { Fundação Pater Beda }\end{array}$ & Sem fluxo constante \\
\hline & $\begin{array}{l}\text { Plano de ação para parcerias } \\
\text { existentes e efetivação de } \\
\text { outras }\end{array}$ & Ausente & Ausente \\
\hline & $\begin{array}{l}\text { Critérios para seleção de } \\
\text { parceiros }\end{array}$ & Integridade e ética & Integridade e ética \\
\hline & $\begin{array}{l}\text { Avaliação dos resultados das } \\
\text { parcerias }\end{array}$ & Ausente & Ausente \\
\hline & $\begin{array}{l}\text { Projetos já realizados na } \\
\text { comunidade com foco no TBC }\end{array}$ & $\begin{array}{l}\text { Roteiros, vivências, } \\
\text { eventos e Famtour }\end{array}$ & $\begin{array}{l}\text { Roteiros, vivências, } \\
\text { eventos e Famtour }\end{array}$ \\
\hline & $\begin{array}{l}\text { Avaliação dos resultados após } \\
\text { finalização dos projetos }\end{array}$ & Existe & Existe \\
\hline & $\begin{array}{l}\text { Continuidade dos resultados } \\
\text { obtidos por meio do projeto }\end{array}$ & $\begin{array}{l}\text { Não foram } \\
\text { identificados }\end{array}$ & $\begin{array}{l}\text { Não foram } \\
\text { identificados }\end{array}$ \\
\hline
\end{tabular}

Fonte - Elaborado pelas autoras, 2019.

A segunda categoria foi gestão de processos que analisou o planejamento estratégico. Na Ilha de Deus, identificou-se o foco no planejamento como um diferencial: "A nossa grande diferença dos outros é esta" (E2). Contudo, durante a pesquisa percebeu-se que este planejamento ocorre de modo muito rudimentar, sem um grau de especialização. A Bomba do Hemetério demonstrou uma grande dependência da RECRIA. Portanto, o déficit nesta categoria não contribui para uma boa governança, ratificando Albuquerque (2016). 0 quadro 11 resume a investigação desta categoria. 
Quadro 11 - Análise da categoria "gestão de processos" nas comunidades pesquisadas

\begin{tabular}{|l|l|l|l|}
\hline \multicolumn{1}{|c|}{$\begin{array}{c}\text { Critérios de } \\
\text { Análise }\end{array}$} & \multicolumn{1}{|c|}{ Critério de Verificação } & Ilha de Deus & $\begin{array}{c}\text { Bomba do } \\
\text { Hemetério }\end{array}$ \\
\hline & Planejamento participativo & Não realiza & Não realiza \\
\hline $\begin{array}{l}\text { Objetivos comuns que representem os } \\
\text { interesses do grupo }\end{array}$ & Existente & Ausente \\
\hline $\begin{array}{l}\text { Reconhecimento Planejamento } \\
\text { Estratégico }\end{array}$ & $\begin{array}{l}\text { Identificação de ações que demonstram } \\
\text { o envolvimento dos participantes na } \\
\text { avaliação do planejamento }\end{array}$ & $\begin{array}{l}\text { Reuniões após } \\
\text { cada projeto }\end{array}$ & $\begin{array}{l}\text { Não foram } \\
\text { identificadas }\end{array}$ \\
\hline & $\begin{array}{l}\text { Metodologias utilizadas para } \\
\text { elaboração coletiva do planejamento }\end{array}$ & $\begin{array}{l}\text { Não houve } \\
\text { planejamento }\end{array}$ & $\begin{array}{l}\text { Não houve } \\
\text { planejamento }\end{array}$ \\
\hline & Fonte - Elaborado pelas autoras, 2019. & \\
\hline
\end{tabular}

A última categoria analisada foi a resiliência, na qual se identificou o compartilhamento de experiências como estímulo aos atores, que comumente têm participado de eventos, feiras, oficinas, entre outros. Há uma preocupação com a sensibilização e a disseminação de valores, que pode ser percebida nos seguintes trechos das entrevistas:

(...) o turismo quando chega a um território, ele leva segurança, sustentabilidade ambiental, leva educação e leva empoderamento comunitário para as pessoas. Faz com que as pessoas percebam que onde eles moram é um território lindo e maravilhoso (E1).

Para você defender a identidade cultural da Ilha de Deus, você tem que investir sempre utilizando o nome da Ilha de Deus em tudo, e ensinando para os nossos jovens, adolescentes e para nossas crianças a valorizar o território (E2).

No quadro 12 constam os critérios investigados e os achados da categoria resiliência nas duas comunidades pesquisadas.

Quadro 12 - Análise da categoria "resiliência" nas comunidades pesquisadas

\begin{tabular}{|c|c|c|c|}
\hline Critério de Análise & Critério de Verificação & Ilha de Deus & Bomba do Hemetério \\
\hline $\begin{array}{l}\text { Compartilhamento } \\
\text { de Experiências }\end{array}$ & $\begin{array}{l}\text { Ações como benchmarking, } \\
\text { intercâmbio de resultados, } \\
\text { melhores práticas, } \\
\text { participação em feiras, } \\
\text { cursos, oficinas, etc. }\end{array}$ & Frequentemente & $\begin{array}{l}\text { Participa, mas } \\
\text { timidamente }\end{array}$ \\
\hline $\begin{array}{l}\text { Desenvolvimento } \\
\text { dos Participantes }\end{array}$ & $\begin{array}{l}\text { Cursos, palestras, eventos } \\
\text { e outras ações para } \\
\text { desenvolver as habilidades } \\
\text { dos participantes }\end{array}$ & $\begin{array}{l}\text { Frequentemente } \\
\text { após a RECRIA }\end{array}$ & $\begin{array}{l}\text { Frequentemente após } \\
\text { a RECRIA }\end{array}$ \\
\hline
\end{tabular}

(continua...) 
Quadro 12 - Continuação.

\begin{tabular}{|l|l|l|l|}
\hline Critério de Análise & \multicolumn{1}{|c|}{ Critério de Verificação } & \multicolumn{1}{|c|}{ Ilha de Deus } & Bomba do Hemetério \\
\hline & $\begin{array}{l}\text { Ações com foco na } \\
\text { disseminação de } \\
\text { valores, símbolos e } \\
\text { atitudes referentes ao } \\
\text { protagonismo coletivo } \\
\text { presentes no destino }\end{array}$ & $\begin{array}{l}\text { Trabalho } \\
\text { realizado com } \\
\text { crianças e } \\
\text { adolescentes } \\
\text { através do Centro } \\
\text { Educacional e Cia } \\
\text { de Dança Nativus }\end{array}$ & $\begin{array}{l}\text { Não foram } \\
\text { identificadas ações }\end{array}$ \\
\hline \multirow{2}{*}{ Sensibilização } & $\begin{array}{l}\text { Situações nas quais atores } \\
\text { sociais presentes no } \\
\text { destino desenvolveram } \\
\text { com abordagem } \\
\text { focada na formação de } \\
\text { multiplicadores do TBC }\end{array}$ & $\begin{array}{l}\text { Não foram } \\
\text { identificadas } \\
\text { ações }\end{array}$ & Não foram \\
\hline identificadas ações
\end{tabular}

Fonte - Elaborado pelas autoras, 2019.

A preocupação com as experiências compartilhadas, desenvolvimento dos participantes e sensibilização, tais posicionamentos em seus discursos contribuem para o enfrentamento das adversidades, superação dos desafios e mudanças como demonstrou Lockwood (2010).

\section{Situação da governança nas iniciativas recifenses}

Após a aplicação do MAG do TBC, percebe-se que na Ilha de Deus se verificou um maior número de critérios atingidos para uma boa governança do que na Bomba do Hemetério. 0 fato das comunidades passarem a integrar a RECRIA serviu para fortalecer os atores mais fracos dentro do processo, ideia essa difundida pelo estudo de González (2014). Contudo, a rede deve atuar no processo de emancipação das comunidades, e não servir como suporte constante que pode reduzir a sua autogestão, como afirmam Cabanilla e Gentili (2015).

Outro fator que influencia maior grau de governança na Ilha de Deus, relaciona-se com a forma como o TBC foi desenvolvido na comunidade, pois mesmo sendo impulsionado por atores externos, o desejo e a formulação para seu planejamento e operação originam-se de um ator endógeno, a ONG Saber Viver. Já a Bomba do Hemetério descobre esta vertente a partir do Programa Bombando Cidadania, implantado na comunidade por agentes exógenos: o Instituto Walmart e o IADH. 0 modo de desenvolvimento do TBC confere à governança da Ilha de Deus uma implementação bottom up enquanto na da Bomba do Hemetério ocorre de maneira top down como explica Hall (2011).

Ainda baseado no estudo de Hall (2011), a governança das iniciativas recifenses de TBC tipifica-se como de redes, pois tenta reunir eficientemente os interesses públicos e privados. Entretanto, ao se examinar as características da governança verifica-se a presença de: (i) flexibilidade e revisão; (ii) experimentação e produção científica; e (iii) debate; porém, sendo deficitária quando se trata da: (iv) participação e divisão do poder; (v) integração multinível; e (vi) diversidade e descentralização; justamente por necessitar maior aproximação com o poder 
público. A RECRIA tem um canal de diálogo aberto com o poder público, mas este ainda não se configura como parte atuante na tomada de decisão.

Diante disso, sabendo que o MAG do TBC se fundamenta no conceito de governança de Martínez (2005), que a entende como a interação horizontal de vários atores da sociedade civil e do poder público através da participação nas esferas políticas, econômicas, sociais e culturais, constata-se que a falta de envolvimento do poder público no planejamento, na operação e na tomada de decisão contribui para a deficiência da governança. Neste momento, faz-se outra crítica ao MAG do TBC posto que Albuquerque (2016), apesar de fundamentar-se na definição acima, prioriza no seu modelo a compreensão e estudo dos agentes endógenos, pois os critérios de análise e verificação não são aplicáveis à relação entre o poder público e os atores comunitários, bem como, a demais agentes externos.

Ademais, considerando o MAG do TBC, constatou-se que a Ilha de Deus possui mais da metade dos critérios de verificação do modelo, enquanto a Bomba do Hemetério manteve-se abaixo da metade destes critérios. Salienta-se que o fato da Ilha de Deus possuir uma ONG há anos estruturada e trabalhando para desenvolver o turismo facilita a obtenção de uma boa governança. A Bomba do Hemetério tem como principal problema a falta de uma liderança integradora. Diante disso, é possível afirmar que a Ilha de Deus possui uma governança em grau regular, mas pode caminhar para a obtenção de uma boa governança. Já na Bomba do Hemetério, a governança é insatisfatória, conforme a análise a partir do MAG do TBC. Por fim, indica-se a necessidade de melhoria em elementos como: comunicação, prestação de contas e gestão de processos. Além de buscar fortalecer atores com baixa desenvoltura na atividade, como é o caso da Bomba do Hemetério.

0 quadro 13 sintetiza os principais achados da pesquisa de campo referentes à dificuldade de consolidação das iniciativas recifenses de TBC, após a análise de suas estruturas de governança.

Quadro 13 - Principais achados referentes à dificuldade de consolidação

\begin{tabular}{|c|c|c|}
\hline & Bomba do Hemetério & Ilha de Deus \\
\hline Governança & $\begin{array}{l}\text { - Forte rivalidade entre os grupos } \\
\text { culturais; } \\
\text { - Ausência de uma liderança } \\
\text { integradora; } \\
\text { - Dependência da subvenção do } \\
\text { setor público; } \\
\text { - Interesses individuais suplantam } \\
\text { os coletivos; } \\
\text { - Forte dependência da RECRIA. }\end{array}$ & $\begin{array}{l}\text { - Baixo relacionamento com } \\
\text { o poder público, contribuindo } \\
\text { para problemas de } \\
\text { infraestrutura; } \\
\text { - Investir numa maior } \\
\text { participação da comunidade na } \\
\text { atividade turística; } \\
\text { - Melhorar a comunicação, } \\
\text { prestação de contas e gestão de } \\
\text { processos. }\end{array}$ \\
\hline
\end{tabular}

Fonte - Elaborado pelas autoras, 2019.

\section{CONCLUSÃO}

0 presente estudo buscou analisar a governança das iniciativas recifenses de TBC pela aplicação do modelo de análise da governança do TBC (MAG do TBC) proposto por Albuquerque (2016). A aplicação deste modelo analítico permitiu 
constatar que a governança na comunidade da Bomba do Hemetério é incipiente, enquanto na Ilha de Deus encontra-se em grau regular.

$\mathrm{Na}$ Bomba do Hemetério, destaca-se a heterogeneidade de seus atores, o que corrobora com os estudos do MTUR (2010) e Pechlaner et al. (2015), bem como, a profusão de conflitos internos, como indicaram Burgos e Mertens (2016), principalmente devido à rivalidade entre as agremiações carnavalescas, que mantêm a disputa mesmo após o período do Carnaval. Sendo assim, o turismo não apresenta reflexos para a comunidade como um todo.

Na Ilha de Deus, destaca-se o relacionamento da comunidade com a fundação alemã Aktionskreis Pater Beda que exige certo grau de organização para enviar o auxílio financeiro para as ações sociais da ONG Saber Viver. Com uma estrutura estável, a entidade exibe um discurso que pretende aproximá-la de um formato mais orgânico e horizontal, embora se perceba uma formação hierarquizada em alguns momentos, provavelmente resquícios de sua criação numa época em que pouco se falava de governança. A comunidade somente é receptora destes benefícios através de ações assistenciais pontuais da ONG que não contempla a todos, ratificando a afirmação de Rogerson (2014), na qual os louros do TBC ficam restritos a poucos.

$\mathrm{Na}$ operacionalização da pesquisa, encontrou-se como principal dificuldade, a deficiência na gestão dos processos das iniciativas recifenses. Os controles ocorrem ainda de maneira muito amadora, sendo assim, muitas das ações desenvolvidas não são devidamente registradas. 0 registro equivocado ou a falta dele complica na coleta de dados, pois nem sempre as informações necessárias encontram-se disponíveis ou fáceis de acessar.

Durante a revisão da literatura, identificou-se lacuna de estudos sobre o perfil da demanda do TBC, carecendo de pesquisas empíricas, por isso, sugere-se um melhor detalhamento deste perfil como uma pesquisa futura. Como contribuição prática, sugere-se que as comunidades devem investir na criação e manutenção de um registro de visitantes, que ofereça material para elaboração de novos projetos e planejamento da atividade, bem como, a adequação de roteiros a partir do público recebido.

Conclui-se que os problemas de governança identificados nas comunidades da Ilha de Deus e da Bomba do Hemetério configuram-se como entraves para a consolidação de suas iniciativas de TBC no mercado turístico. Vale salientar que esta pesquisa foi realizada antes da pandemia de Covid- 19 e acredita-se que o contexto pandêmico tenha agravado os problemas anteriormente detectados.

Por fim, cabe o registro de que este artigo é fruto de uma dissertação de mestrado defendida no Programa de Pós-Graduação em Hotelaria e Turismo da Universidade Federal de Pernambuco.

\section{REFERÊNCIAS}

Albuquerque, M. C. F. de. (2016). Modelo de Análise da Governança do TBC: Uma proposição adaptativa a partir de diversos olhares. Universidade Federal de Pernambuco. https://repositorio.ufpe.br/handle/123456789/20566

Anjos, F. A., \& Kennell, J. (2019). Tourism, governance and sustainable development. Sustainability (Switzerland), 11(16), 1-6. https://doi.org/10.3390/su11164257

Bardin, L. (2016). Análise do Conteúdo. São Paulo: Edições 70. 
Bell, J. (2008). Projeto de pesquisa: guia para pesquisadores iniciantes em educação, saúde e ciências sociais. Porto Alegre: Artmed.

Blackstock, K. (2005). A critical look at community based tourism. Community Development Journal, 40(1), 39-49. http://www.jstor.org/stable/44258928

Burgos, A., \& Mertens, F. (2016). As redes de colaboração no turismo de base comunitária: implicações para a gestão participativa. Tourism \& Management Studies, 12(2), 18-27. https://doi.org/10.18089/tms.2016.12203

Burgos, A., \& Mertens, F. (2017). Participatory management of community-based tourism: a network perspective. Community Development, 48(4), 546-565. https://doi.org/ 10.1080/15575330.2017.1344996

Bursztyn, I., \& Bartholo, R. (2012). O processo de comercialização do turismo de base comunitária no Brasil: desafios, potencialidades e perspectivas. Sustentabilidade Em Debate, 3(1), 97-116. https://doi.org/10.18472/SustDeb.v3n1.2012.7198

Cabanilla, E., \& Gentili, J. (2015). Características de las páginas de la Internet de turismo comunitario en países de América. Una aproximación desde el análisis de contenidos y la cartografía temática. Pasos Revista de Turismo y Patrimonio Cultural, 13(1), 157-174. https://doi.org/10.25145/j.pasos.2015.13.011

Cozzolino, F., Irving, M. D. A., \& Soares, D. G. (2015). Gestão de Áreas Protegidas: análise dos marcos legais à luz dos princípios de governança democrática. Sociedade e Território, 27(1),138-156. https://periodicos.ufrn.br/sociedadeeterritorio/article/ download/4950/5661/.

Creswell, J. W. (2016). Projeto de pesquisa: métodos qualitativo, quantitativo e misto (3rd ed.). Porto Alegre: Artmed.

Fabrino, N. H., Nascimento, E. P. , \& Costa, H. A. (2016). Turismo de Base Comunitária : uma reflexão sobre seus conceitos e práticas. Caderno Virtual de Turismo, 16(3), 172-190. https://doi.org/10.18472/cvt.16n3.2016.1178

Fernandes, L. M. M., \& Coriolano, L. N. M. T. (2015). A governança na política nacional de regionalização do turismo: estudo dos grupos gestores dos destinos indutores do Ceará. Revista Turismo Visão e Ação, 17(2), 247-278. https://doi.org/Doi: 10.14210/ rtva.v17n2.p247-278

Giampiccoli, A., \& Saayman, M. (2018). Community-based tourism development model and community participation. African Journal of Hospitality, Tourism and Leisure, 7(4), 1-27. https://www.ajhtl.com/uploads/7/1/6/3/7163688/article_16_vol_7_4_2018.pdf

Gómez, C. R. P., Falcão, M. C., Castillo, L. A. G., Correia, S. N., \& Oliveira, V. M. (2015). Turismo de Base Comunitária como Inovação Social: congruência entre os constructos. PASOS. Revista de Turismo y Patrimonio CulturalRevista de Turismo y Patrimonio Cultural, 13(5), 1213-1227. https://doi.org/10.25145/j.pasos.2015.13.082

González, M. V. (2014). Gobernanza turística: ¿Políticas públicas innovadoras o retórica banal? Governança. Caderno Virtual de Turismo, 14(supl.1), 9-22. http://www.ivt. coppe.ufrj.br/caderno/index.php/caderno/article/view/1023

Hall, C. M. (2011). A typology of governance and its implications for tourism policy.Journal of Sustainable Tourism, 19(June), 437-457.https://doi.org/10.1080/09669582.2011.570346

Leão, A. L. M. de S., \& Pereira, E. L. (2018). A Cultura carnavalesca da Bomba do Hermetério como recurso econômico. Desenvolvimento Em Questão, 16(42), 1-19. https://doi.org/ 10.21527/2237-6453.2018.42.484-517

Lockwood, M. (2010). Good governance for terrestrial protected areas: A framework, principles and performance outcomes. Journal of Environmental Management, 91(3), 754-766. https://doi.org/10.1016/j.jenvman.2009.10.005 
Martínez, A. C. (2005). La gobernanza hoy: Introducción. In La gobernanza hoy: 10 textos de referencia (pp. 11-36). Madrid: Instituto Nacional de Administración Pública.

Mayaka, M., Croy, W. G., \& Cox, J. W. (2018). Participation as motif in community-based tourism: a practice perspective. Journal of Sustainable Tourism, 26(3), 416-432. https://doi.org/10.1080/09669582.2017.1359278

Mielke, E. J. C., \& Pegas, F. V. (2013). Turismo de Base Comunitária no Brasil. Insustentabilidade é uma Questão de Gestão. Turismo Em Análise, 24(1), 170-189. https://doi.org/ 10.11606/issn.1984-4867.v24i1p170-189

Moraes, F. M. de, \& Marques, G. V. G. (2017). Planejamento urbano e participação popular: a experiência do plano de ação integrada de investimentos para a ZEIS Ilha de Deus, Recife - Pernambuco. Encontro Nacional Da Rede Observatório Das Metrópoles, 1-16. Natal. https://cchla.ufrn.br/rmnatal/evento_2017/anais/ST4/planejamento_urbano.pdf

Mtapuri, O., \& Giampiccoli, A. (2020). Toward a model of just tourism: A proposal. Social Sciences, 9(4), 1-19. https://doi.org/10.3390/socsci9040034

MTUR, M. do T. (2008). Edital MTUR n. 001/2008: seleção de propostas de projetos para apoio às iniciativas de turismo de base comunitária. Brasília: Ministério do Turismo, 2008.

MTUR, M. do T. (2010). Dinâmica e Diversidade do Turismo de Base Comunitária: desafio para a formulação de política pública. Retrieved from http://www.turismo.gov.br/ export/sites/default/turismo/o_ministerio/publicacoes/downloads_publicacoes/

Okazaki, E. (2008). A community-based tourism model: Its conception and use. Journal of Sustainable Tourism, 16(5), 511-529. https://doi.org/10.1080/09669580802159594

Pechlaner, H., Beritelli, P., \& Volgger, M. (2015). Introduction: Emerging Landscape of Destination Governance. In Contemporary Destination Governance: A Case Study Approach (pp. vii-xvi). Retrieved from http://dx.doi.org/10.1108/S2042144320140000006055\%0ADownloaded

Rogerson, C. M. (2014). Informal Sector Business Tourism and Pro-poor Tourism: Africa's Migrant Entrepreneurs. Mediterranean Journal of Social Sciences, 5(16), 153-161. https://doi.org/10.5901/mjss.2014.v5n16p153

Villavicencio, B. P., Zamora, J. G., \& Pardo, G. L. (2016). El Turismo Comunitario en la Sierra Norte de Oaxaca: Perspectiva desde las instituciones y la gobernanza en territorios indígenas. El Periplo Sustentable, 30(Enero/Junio), 6-37. Retrieved from http://ru.iiec. unam.mx/id/eprint/3137

Zielinski, S., Kim, S. il, Botero, C., \& Yanes, A. (2020). Factors that facilitate and inhibit community-based tourism initiatives in developing countries. Current Issues in Tourism, 23(6), 723-739. https://doi.org/10.1080/13683500.2018.1543254

Recebido em: 03/04/2021

Aprovado em: 22/08/2021

\section{CONTRIBUIÇÕES}

Pollyanna Fraga Graciano: Definição do problema de pesquisa e objetivos, desenvolvimento da proposição teórica, realização da revisão bibliográfica e fundamentação teórica, escolha dos procedimentos metodológicos, coleta de dados, análise de dados, elaboração de tabelas, gráficos e figuras, redação do manuscrito e adequação do manuscrito às normas da RTA.

Luciana Araújo de Holanda: Definição do problema de pesquisa e objetivos, desenvolvimento da proposição teórica, escolha dos procedimentos metodológicos, revisão crítica do manuscrito, redação do manuscrito e adequação do manuscrito às normas da RTA. 